\title{
THE USE OF ELECTRONIC INTEGRATED TEXT, VOICE, AUDIO QUESTIONNAIRE (EITVAQ) IN ASSESSING THE QUALITY OF LIFE AMONG CHILDREN WITH HYDROCEPHALUS.
}

\section{Alkooheji, JE Tan, J Caird, AJ Nicholson}

\section{Introduction:}

Current questionnaire for hydrocephalus don't adequately present the patient's quality of life because they are usually in text format and require assistance to complete. This study aims to validate that the Electronic Integrated Text,Visual, Audio Questionnaire (EITVAQ) is a reliable tool in the assessment of the quality of life of patients with hydrocephalus than the current healthrelated quality of life (HRQOL) questionnaires.

\section{Aims}

To adapt EITVAQ (Electronic Integrated Text,Visual, Audio Questionnaire) into a phone/tablet application to gain widespread usage of EITVAQ by multidisciplinary teams.

\section{Methods:}

The study is a randomized single-blinded crossover prospective study over 12 months period to assess the reliability and validity of the EITVAQ.There are 31 questions that fall into four primary domains of health; Physical, Social, Emotional, Cognitive. Each question has five choices; Never (I), Seldom (2), Sometimes (3), Mostly (4), and Always (5).

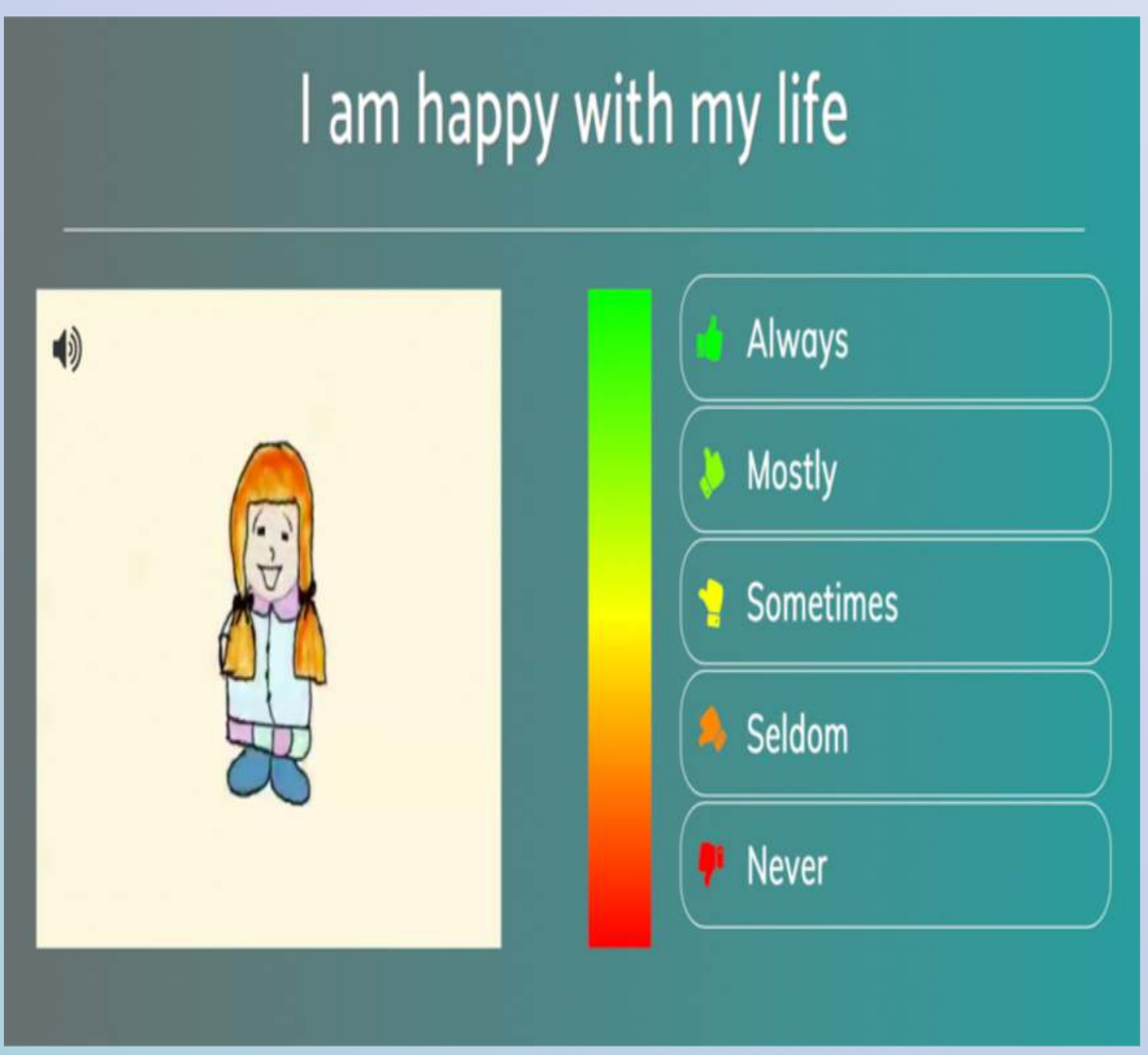

\section{Results:}

A total of 27 patients attempted the questionnaire with 24 patients completing the survey and an average time of completion of 5 minutes 54 seconds. The mean of each domain was calculated on a scale from I (strongly disagree) to 5 (strongly agree), and they were; Physical -4.06 , Cognitive - 3.98, Emotional - 3.83, and Social - 3.8I.
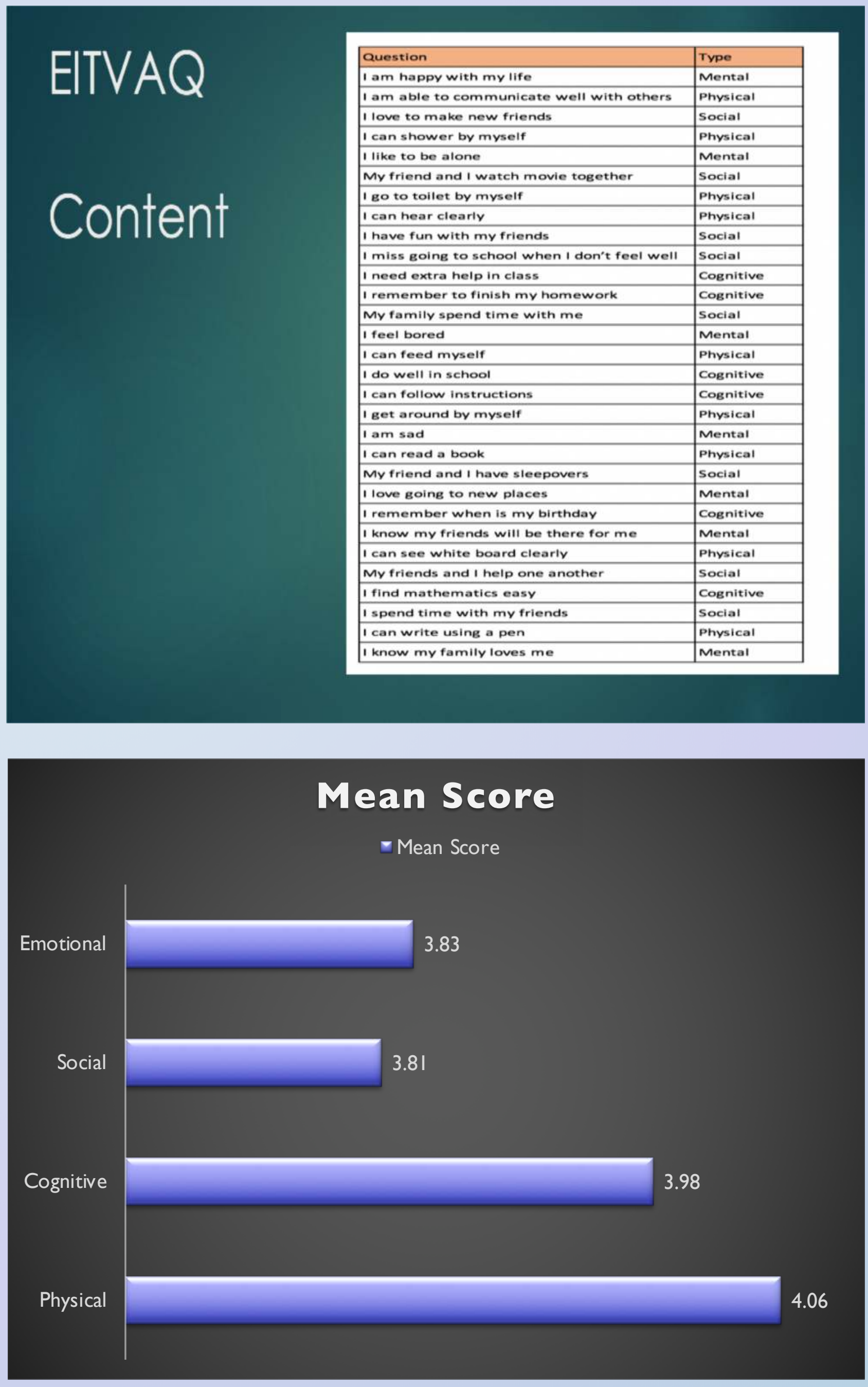

\section{Conclusions:}

The study is still in progress, and final results may differ from the analyzed data shown here. Current data from the EITVAQ questionnaire is similar to that from other HRQOL surveys that assess hydrocephalus patients. However, further data must be collected to provide a definitive validation. 